\title{
Comparison of Ultrasound Guided Interscalene and Supraclavicular Brachial Plexus Block along with Superior Cervical Plexus Block for Clavicle Fracture Surgery
}

\author{
Lalit Kumar Rajbanshi, ${ }^{1}$ Batsalya Arjyal, ${ }^{1}$ Kanak Khanal, ${ }^{1}$ Akriti Bajracharya ${ }^{1}$ \\ ${ }^{1}$ Birat Medical College and Teaching Hospital, Biratnagar, Morang, Nepal.
}

\begin{abstract}
Background: The interscalene brachial plexus block combined with superior cervical plexus block is frequently used for the clavicle surgery. This study was conducted to compare interscalene approach with the supraclavicular approach for brachial plexus block used for clavicle surgery. Materials and Methods: This was prospective comparative study conducted for two years in tertiary care hospital. Sixty patients with clavicle fracture with ASA I and II were randomly divided into two equal groups; ISBPB (interscalene approach) and SCBPB (supraclavicular approach). Both of these blocks were combined with superior cervical plexus block. Ultrasound was used to perform all the blocks. Primary outcome for the comparison was block characteristics, which included sensory and motor block onset, duration, and block satisfaction. The secondary variables used for comparison were analgesic properties and complications. Results: Supraclavicular brachial plexus had rapid onset of sensory and motor block and was statistically significant $(\mathrm{P}<0.05)$ as compared to interscalene approach. Similarly, SCBPB had significantly longer duration of sensory block $(\mathrm{P}=0.003)$. The duration of motor block was comparable between the blocks. The intraoperative pain score (VAS), requirement of rescue analgesia with in 24 hours of surgery and complications related with the procedures were comparable between the two groups. Majority of the patients were satisfied with either of the approach for brachial plexus block. Conclusions: Supraclavicular brachial plexus block combined with superior cervical plexus block provided equally effective and adequate anesthesia and analgesia for clavicle surgery with comparable complications as compared to interscalene approach.
\end{abstract}

Keywords: brachial Plexus block; cervical plexus block; interscelene; supraclavicular approach.

\section{INTRODUCTION}

Brachial plexus block combined with superior cervical block can be a safe and effective option for anesthesia and analgesia for clavicle surgery. ${ }^{1,2,3}$ The clavicle is jointly supplied by the innervation from the brachial plexus and cervical plexus. Lateral two third of clavicle is supplied by upper roots of brachial plexus (C5 and C6) while medial one third is supplied by cervical plexus. The proximal block of brachial plexus can be achieved either by interscalene or supraclavicular approach. The interscalene approach has been used frequently for the clavicle surgery, as one of the advantages of this block is that it partially blocks the cervical plexus also. Similarly, supraclavicular approach provides a blockade at the level where all the three trunks are tightly arranged below the mid point of clavicle, thus ensuring effective anesthesia to the upper limb. ${ }^{4}$ The cervical plexus originates from the $\mathrm{C} 2, \mathrm{C} 3$ and $\mathrm{C} 4$ nerve root supplying the same dermatome. The blockage of cervical plexus provides anesthesia over fascia and skin above the clavicle up to the region of acromion. ${ }^{5}$ Due to the varied innervation of the clavicle, not a single nerve block is sufficient to provide adequate anesthesia and analgesia. Thus, the brachial plexus block is frequently combined with cervical plexus block for clavicle surgery.

Use of Ultrasound for brachial plexus and cervical plexus block makes the procedure more effective and risk free. The unwanted complications of supraclavicular brachial plexus block like pneumothorax, vascular injuries, drug toxicity can be minimized by the use of ultrasound. ${ }^{6}$ However supraclavicular brachial plexus block is less commonly used for clavicle surgery, as there is high probability of missing C5 and C6 dermatome supply. The use of ultrasound for brachial plexus block has

Correspondence: Dr. Lalit Kumar Rajbanshi, Department of Anesthesiology and Critical Care, Birat Medical College and Teaching Hospital, Biratnagar, Morang, Nepal. Email: lalitrajbanshi@gmail.com. Phone: +9779852030496. DOI: 10.3126/jcmsn.v14i4.20635. Article received: 2018-07-29. Article accepted: 2018-12-13. 
tremendously improved the success rate and minimized the complications.

Interscalene brachial plexus block combined with superior cervical plexus block has been used widely for clavicle surgery but the use of supraclavicular brachial plexus block has limited evidence for this purpose. So, this study was conducted to compare the efficacy and safety of supraclavicular and interscalene brachial plexus block combined with cervical plexus block for clavicle surgery.

\section{MATERIALS AND METHODS}

This was a prospective comparative study conducted at Birat Medical College and Teaching Hospital, a tertiary care hospital in the eastern part of Nepal. The study duration was from April 2016 to March 2018 (two years) and institutional clearance for the approval of the study was obtained before conducting the study. A total of 60 patients of both the sex planned for clavicle fracture surgery with the age more than 16 years and ASA I and II were included in the study. Patients with hypersensitivity to local anesthetics coagulopathy, infection at the site of block, haemodynamicaly unstable, respiratory insufficiency, neurological deficit on the side of surgery, hemi diaphragmatic palsy, congestive heart failure, symptomatic arrhythmia, electrolyte imbalance and uncooperative patients were excluded.

The participants were randomly divided in to two equal groups with 30 in each. The first group named as ISBPB received interscalene brachial plexus block while second group named as SCBPB received supraclavicular brachial plexus block. Both the blocks were combined with ultrasound guided superficial cervical plexus block. The same anesthesiologist who is trained in ultrasound guided regional blocks performed block in all the patients while the patient and the investigator who was recording the block characteristics were unaware of the approach of the block, type of local anesthetic used. Pre anesthetic check up was done for all the patients and premedication was done as per standard protocol. On the day of surgery, intravenous access was secured with wide bored cannula and noninvasive monitoring was done with electrocardiogram, noninvasive blood pressure and pulse oximetry.

The choice of brachial plexus block was made by computer-generated randomization. The interscalene groove at the level of cricoid cartilage was identified lateral to the lateral border of sternocleidomastoid muscle and the area was cleaned with chlorhexidine and alcohol. An ultrasound machine (Samsung, Mysono 6) with linear probe (5-12 $\mathrm{MHz}$ ) was used to scan the $\mathrm{C} 5, \mathrm{C} 6$ and $\mathrm{C} 7$ nerve root in between anterior and middle scalene muscle. Two $\mathrm{ml}$ of $2 \%$ lignocaine with adrenaline (1:200000) was used to provide skin anesthesia. The C5, C6 and C7 nerve roots were best identified and $20 \mathrm{ml}$ of $0.25 \%$ bupivacaine was injected at the vicinity of the roots with the help of $50 \mathrm{~mm}, 22 \mathrm{~g}$ peripheral nerve block needle.

For supraclavicular block, the patient was placed in supine with the head turned opposite to the site of block. The linear probe $(5-12 \mathrm{MHz})$ was placed at the supraclavicular fossa just above the mid point of clavicle and the distal trunks of the brachial plexus block were identified above and lateral to the subclavien artery. Again $2 \mathrm{ml}$ of $2 \%$ lignocaine with adrenaline was injected to provide skin anesthesia. A $50 \mathrm{~mm} 22 \mathrm{~g}$ peripheral nerve block needle was used via in plane method from lateral to medial to inject $20 \mathrm{ml}$ of $0.25 \%$ bupivacaine around the nerve trunks of brachial plexus.

Both of the above blocks were combined with superficial cervical plexus block. The patient was placed in semi recumbent position with the head turned opposite side. A linear probe (5-12 MHz) was used to scan the area lateral to the posterior border of sternocleidomastoid muscle at its midpoint. $10 \mathrm{ml}$ of $0.25 \%$ bupivacaine was injected along the fascial plane separating posterior border of sternocleidomastoid muscle and anterior scalene muscle. Once all the blocks were performed successfully, another investigator who was unaware of the type brachial plexus block performed the outcome assessment.

The primary outcome of the study was to compare the block characteristics (onset, duration and strength of sensory and motor blocks) between the two groups. The secondary outcomes were comparing the analgesic property and complication of the interscalene and brachial plexus blocks. The sensory and motor function of the blocks was assessed immediately after the block and every 10 minutes interval until 30 minutes. The sensory function of the block was evaluated by cold sensation with the help of alcohol soaked swab on the surgical dermatome (C3-C5). This was compared with the contralateral dermatome. The strength of the sensory block was measured by 3 point scale; $0=$ 
no difference from unblocked site, $1=$ less cold sensation from unblocked site and $2=$ no sensation felt. Similarly, motor function was assessed by asking the patient to abduct the thumb (radial nerve), pinch thumb and finger (median nerve), abduct the fingers (Ulnar nerve) and flexion of the forearm at elbow joint (musculocutaneous nerve). The motor strength was measured again in three point scale; $0=$ no motor block (performing the task without difficulty), $1=$ partial motor block (performing the task with slight difficulty), 2= complete motor block (not able to perform the task).

The onset of sensory and motor block was defined as the time duration from injection of the drug and recording point one in the scale for both the function. Similarly duration of sensory block was defined as the time duration from drug injection to first requirement of rescue analgesic or patient complaining of pain. The duration motor block was from the time of drug injection to the point to decrease one or less on measurement scale.

Surgical pain was assessed in the intraoperative time, immediately in the post anesthesia care unit (PACU) and at 6 hours, 12 hours and 24 hours after the surgery. Visual analogue scale (VAS) was used to assess pain that measured 0 as no pain at all and 10 the worst pain experienced.

The requirement of the analgesia in intraoperative time and with in 24 hours of surgery was also recorded. Fentanyl 0.5 microgram $/ \mathrm{kg}$, acetaminophen ( 0.5 to $1 \mathrm{gm})$ were the rescue analgesic used intraopertively and in PACU. Intravenous midazolam (1-2mg) was used as a sedative to enhance the comfort of the patient and one $\mathrm{mg}$ of bolus dose of same was repeated intermittently whenever required. The complications of the blocks were recorded and compared accordingly.

Considering the effect size of 17 and standard deviation of 32 on the basis of previous study done by Taeha Ryu et $\mathrm{al}^{7}$ and $10 \%$ drop out, the sample size needed for statistically significant outcome was calculated to be 60 . The study included 5\% acceptable level of significance (type I error) and $80 \%$ of power of study. The data were collected in MS excel and statistical analysis was done with the help of IBM SPSS statistics version 23. The continuous data were interpreted as mean, median, range and standard deviation while categorical data were presented as frequency and percentage. ChiSquare and Mann -Whitney test were used for the analysis of the data. Box plot was used to demonstrate the median and range of continuous data. $P$ value less than 0.05 was considered statistically significant.

\section{RESULTS}

Out of 60 participants in the study, two patients from ISBPB group and three patients from SCBPB were excluded from the study because of inadequate effect and conversion to general anesthesia. The demographic profile, ASA grading and the time taken for surgical procedure in both the group were non significant (Table 1).

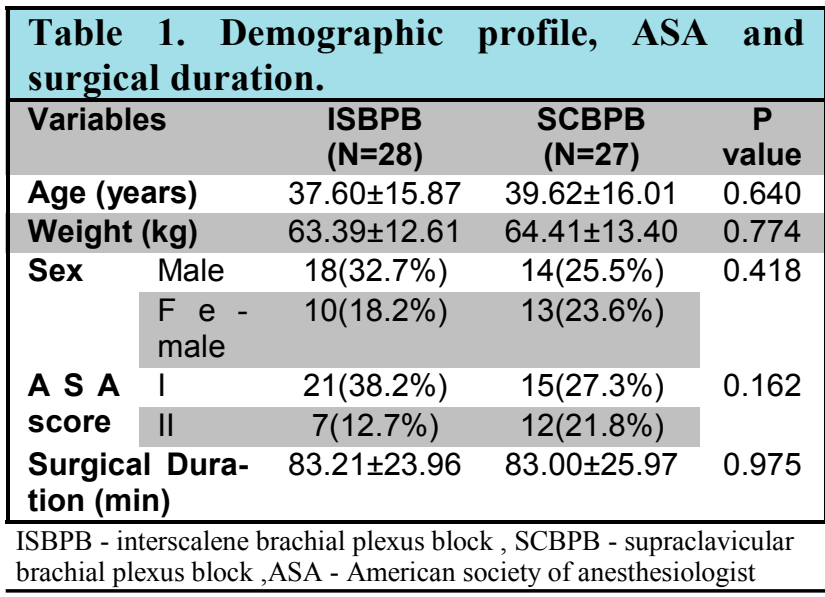

The block characteristics is demonstrated in Table 2. It was observed that the patients with the supraclavicular approach for the brachial plexus block had significantly rapid onset of sensory and motor block as compared to the interscalene approach ( $\mathrm{P}$ value $<0.05)$. The effect of the sensory block remained for significantly longer duration in supraclavicular approach as compared to interscalene approach $(p=0.003)$ while the duration

\begin{tabular}{|c|c|c|c|c|}
\hline \multicolumn{2}{|c|}{ Variables } & $\begin{array}{l}\text { ISBPB } \\
(\mathrm{N}=28)\end{array}$ & $\begin{array}{l}\text { SCBPB } \\
(\mathrm{N}=27)\end{array}$ & $\begin{array}{c}P \\
\text { value }\end{array}$ \\
\hline \multicolumn{2}{|c|}{$\begin{array}{l}\text { Volume of An- } \\
\text { esthesia }(\mathrm{ml})\end{array}$} & 20.00 & 20.00 & \\
\hline \multicolumn{2}{|c|}{$\begin{array}{l}\text { Onset of sen- } \\
\text { sory block } \\
\text { (min) }\end{array}$} & $11.00 \pm 3.12$ & $8.39 \pm 2.68$ & 0.002 \\
\hline \multicolumn{2}{|c|}{$\begin{array}{l}\text { Onset of motor } \\
\text { block (min) }\end{array}$} & $13.94 \pm 3.81$ & $\begin{array}{c}11.80 \pm 4.1 \\
0\end{array}$ & 0.046 \\
\hline \multicolumn{2}{|c|}{$\begin{array}{l}\text { Duration of sen- } \\
\text { sory block } \\
\text { ( min) }\end{array}$} & $\begin{array}{c}438.93 \pm 125 \\
57\end{array}$ & $\begin{array}{c}563.70 \pm 1 \\
62.12\end{array}$ & 0.003 \\
\hline \multicolumn{2}{|c|}{$\begin{array}{l}\text { Duration of mo- } \\
\text { tor block (min) }\end{array}$} & $\begin{array}{c}346.71 \pm 113 \\
25\end{array}$ & $\begin{array}{c}392.48 \pm 1 \\
23.45\end{array}$ & 0.160 \\
\hline \multirow[t]{2}{*}{$\begin{array}{l}\text { B I o c k } \\
\text { s a t is - } \\
\text { faction }\end{array}$} & $\begin{array}{l}\text { Fully } \\
\text { satis- } \\
\text { fied }\end{array}$ & $22(40.7 \%)$ & $\begin{array}{c}19 \\
(35.2 \%)\end{array}$ & 0.754 \\
\hline & $\begin{array}{l}\text { Un - } \\
\text { satisfi } \\
\text { ed }\end{array}$ & $6(11.1 \%)$ & $7(13.0 \%)$ & \\
\hline
\end{tabular}


of motor block was comparable between the two groups. Majority of the patients in both groups were satisfied $(40.7 \%$ and $35.2 \%)$ with the procedure and willing to go for the same kind of procedure in future if needed.

Pain score was assessed using visual analogue scale during intraoperative time, immediately in the post anesthesia care unit (PACU), 6,12 and 24 hours after the surgery. The number of patients requiring analgesia (if VAS score more than 4) in intraoperative time and within 24 hour of surgery was compared between the groups and result was shown in Table 3. Fentanyl (50-100 mcg) and acetaminophen $(500-1000 \mathrm{mg})$ were given to the patient complaining of pain and VAS score more than 4 . The rescue analgesia requirement was comparable between the two groups.

\begin{tabular}{|c|c|c|c|}
\hline Variables & $\begin{array}{l}\text { ISBPB } \\
(\mathbf{N}=\mathbf{2 8})\end{array}$ & $\begin{array}{l}\text { SCBPB } \\
(\mathrm{N}=27)\end{array}$ & P Value \\
\hline $\begin{array}{l}\text { Analgesia re- } \\
\text { quirement In- } \\
\text { traoperative }\end{array}$ & $5(9.1 \%)$ & $7(12.7 \%)$ & 0.528 \\
\hline $\begin{array}{l}\text { Analgesia re- } \\
\text { quirement } \\
\text { within } 24 \text { hrs. }\end{array}$ & $9(16.7 \%)$ & $13(24.1 \%)$ & 0.260 \\
\hline
\end{tabular}

ISBPB - interscalene brachial plexus block, SCBPB - supraclavicular brachial plexus block

The intraoperative pain assessment done by visual analogue scale was shown in Figure 1. The median VAS score in the two groups was two. The range

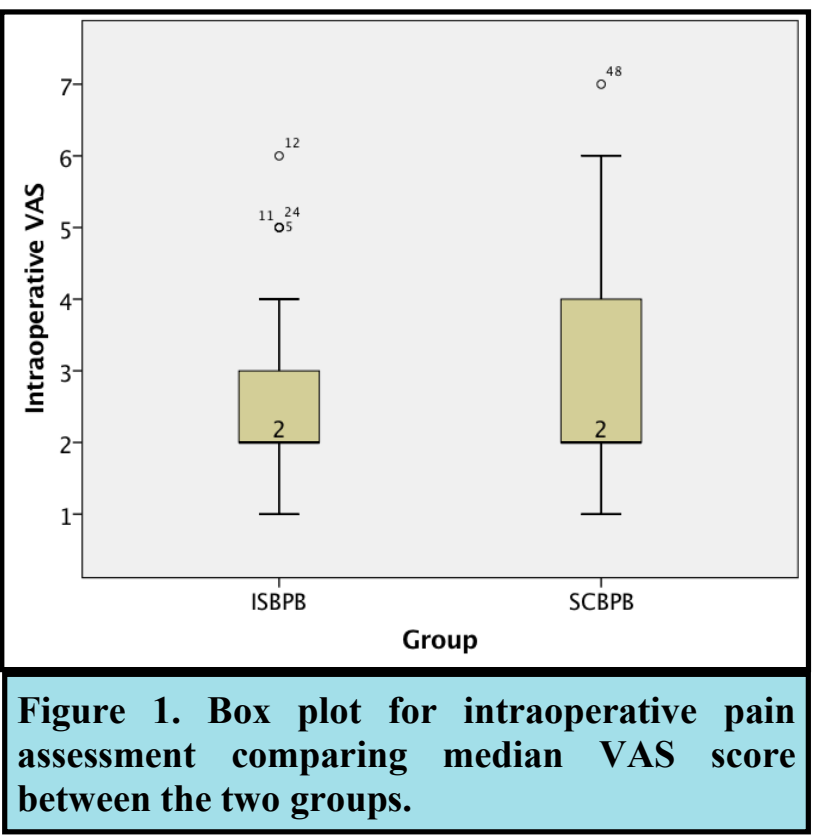

for the VAS score was wider (1-6) in patients with supraclavicular approach as compared to the interscalene approach.

Complications related to the procedure itself and anesthetic drugs were monitored during the procedure and within 24 hours of the procedure (Table 4). Four patients developed Horner's syndrome in interscalene group while only one patient from supraclavicular approached had this complication. The complication was not of clinical significance as all the cases were managed symptomatically. Similarly vascular puncture was seen in more number of patients in supraclavicular approach. Arrhythmia was another complication that was noticed in four patients with SCBPB group and two patients with ICBPB group. None of the patients in the study had pneumothorax.

\begin{tabular}{|llll|}
\hline $\begin{array}{l}\text { Table 4. Comparison of complications between } \\
\text { the two groups. }\end{array}$ & $\begin{array}{l}\text { ISBPB } \\
\text { (N=28) }\end{array}$ & $\begin{array}{l}\text { SCBPB } \\
\text { (N=27) }\end{array}$ & $\begin{array}{l}\text { P } \\
\text { value }\end{array}$ \\
\hline Variables & $4(7.3 \%)$ & $1(1.8 \%)$ & 0.352 \\
Horner's syndrome & $4(7.3 \%)$ & $2(3.6 \%)$ & 0.413 \\
Hoarseness of Voice & $4(5.5 \%)$ & $5(9.1 \%)$ & 0.469 \\
Vascular Puncture & $3(3.6 \%)$ & $4(7.3 \%)$ & 0.422 \\
Arrhythmia & $2(3.6)$ & 0 & NA \\
\hline Pneumothorax & 0 & 0 &
\end{tabular}

ISBPB - interscalene brachial plexus block, SCBPB - supraclavicular brachial plexus block

\section{DISCUSSION}

Brachial plexus block alone is not sufficient to provide anesthesia and analgesia for the clavicle surgery as the anterior superior part of shoulder and clavicle has dual nerve supply from brachial plexus and cervical plexus. Interscalene approach is frequently used to block the brachial plexus nerve root for clavicle surgery. The use of regional anesthesia for clavicle surgery ameliorates the complications of general anesthesia and can lead to opioid free anesthesia, early ambulation and shorter hospital stay. ${ }^{8}$ Supraclavicular as well as interscalene can be effectively used to block the brachial plexus for achieving anesthesia for clavicle surgery. The supraclavicular approach was not used very frequently in earlier days because of its high incidence of pneumothorax and vascular puncture. ${ }^{9,10}$ The use of ultrasound in todays era has made this procedure safe and effective for using even for clavicle surgery. ${ }^{11}$ So, this study has compared the anesthetic property of interscalene and supraclavicular approach for clavicle surgery under the guidance of ultrasound.

The present study included participants with comparable demographic profiles, ASA status and 
surgical duration in between the two groups. All the blocks were performed under ultrasound guided technique and the block characteristics in the form of onset, duration of sensory and motor effect and block satisfaction were observed. The onset of the motor and sensory effect was significantly rapid for supraclavicular approach as compared to interscalene approach. The trunk and the divisions of the brachial plexus are compactly arranged in the midpoint of clavicle at the supraclavicular region. This might be the possible reason for rapid onset of the block effect. A study conducted by Bharti $\mathrm{N}$ and et al had also demonstrated that the block onset time was significantly rapid in supraclavicular brachial plexus block. ${ }^{12}$ It is difficult to visualize the $\mathrm{C} 8$ and $\mathrm{T} 1$ nerve root even with the use of ultrasound during interscalene approach thus increasing the possibility of missing the lower nerve root supply. On the other hand, the inferior trunk forming $\mathrm{C} 8$ to $\mathrm{T} 1$ is better visualized in ultrasound guided supraclavicular approach. ${ }^{13}$ Besides, there is a cephaloid spread of the anesthetic drug into the interscalene groove thus producing a rapid and more intense block with the supraclavicular injection of the anesthetic drugs. ${ }^{14}$

The present study observed that there was a significant difference in the duration of sensory block. The patients in SCBPB group had significantly longer duration of sensory block as compared to patients with ISBPB $(\mathrm{P}=0.003)$. Similarly, duration of motor block was also higher for SCBPB group but was statistically not significant. The similar results had been observed in the study conducted by Chun Woo Yang and et al and Bhattacharya $\mathrm{S}$ and et al. ${ }^{15,16}$ It was possible that the direct injection of the anesthetic drugs in the close vicinity of the compactly arranged divisions and trunks of brachial plexus in the supraclavicular region might have contributed prolong anesthetic effect in supraclavicular approach.

The C5 and C6 and less frequently C7 nerve root are well visualized in ultrasound guided interscalene brachial plexus block and can easily be blocked but the procedure usually spares inferior trunk (C8 and T1). ${ }^{7}$ However, The clavicle surgery requires anesthesia only in the $\mathrm{C} 3$ to $\mathrm{C} 6$ dermatome. ${ }^{5}$ As the superior and anterior part of clavicle is supplied by $\mathrm{C} 3$ to $\mathrm{C} 6$ nerve root, the interscalene brachial plexus block can be combined with superior cervical plexus to achieve an effective surgical anesthesia for clavicle surgery. The supraclavicular approach can sometimes spare the upper trunk (C5 and C6) but cephaloid spread of the anesthetic drugs into the interscalene groove can make it to achieve sufficient surgical anesthesia for clavicle surgery. The study observed variation in the onset and duration of the block between the two groups but majority of the patient in both the group had adequate surgical anesthesia and analgesia for surgery.

The visual analogue scale used for the assessment of the pain during and after the surgical procedure was comparable between the two groups. The median VAS score was two in both the group. But the patient in supraclavicular approach (SCBPB) showed wide range of the pain score variation as compared to the patient in interscalene approach (ISBPB). As discussed previously, the upper trunk (C5 and C6) might be spared during supraclavicular approach leading to higher pain score in some of the cases. Only a very few patients in either group required the rescue analgesia in the form of intravenous fentanyl and acetaminophen during intraoperative and within 24 hours of surgery. It was comparable and statistically non significant between the groups. This observation showed that the block effect was adequate in either of the approach. The study observed that the majority of the patients were well satisfied with either of the procedures and willing to go for the same if needed in the future. The possible reason behind good patient satisfaction could be well-controlled pain during and after the surgery, early mobilization of the patient and shorter hospital stay.

In the present study, the complications associated with the interscalene and supraclavicular brachial plexus block were Horner's syndrome, hoarseness of voice, vascular puncture and arrhythmia. The observed complications were related to the procedure itself and the anesthetic drug used for the block. Horner's syndrome was seen more frequently in patients with interscalene approach due to close proximity of the cervical sympathetic chain. The incidence of Horner's syndrome during interscalene and supraclavicular block ranges from 1\%-75\% and has negligible clinical significance. ${ }^{17,18,19}$ In all the cases of Horner's syndrome, the clinical status of the patient improved with the resolution of the effect of anesthetic drugs.

Ultrasound guided technique had increased the precision for drug injection at the close vicinity of the nerve structure thus minimizing the complications like phrenic nerve palsy and vascular puncture in both the study group. ${ }^{20}$ Similarly the 
drug related arrhythmia was also very less in both the group. None of the patients in the study group developed pneumothorax. All the complications were statistically non significant between the groups.

\section{Limitations}

All the blocks were performed by a single anesthesiologist, which had limited in generalizing the results. On the other hand, the blocks characteristics were measured by different observers, which might have raised the possibility of observer variability in the outcome. Superior cervical plexus blocks provide potent anesthetic effect at the medial and anterior aspect of the clavicle. Combining superior cervical plexus block with the supraclavicular and interscalene brachial plexus block might be the confounding factor for the adequacy of the block in both the groups.

\section{CONCLUSIONS}

The supraclavicular brachial plexus block provided intense level of sensory and motor block with the rapid onset and longer duration of block effect as compared to interscalene approach. The intraoperative and postoperative analgesic requirements were minimum and were comparable between the two groups. The use of ultrasound had minimized the complications related with the procedures and drugs and was comparable between the groups. Hence, it can be concluded that supraclavicular approach while combined with superior cervical plexus block might be equally effective as compared to the interscalene approach in providing anesthesia and analgesia for clavicle surgery.

\section{ACKNOWLEDGEMENTS}

The author would like to thank all the patients for giving consent to participate in the study.

\section{Conflict of Interest: None}

\section{REFERENCES}

1. Dillane D, Ozlsel T, Gadbois K.Anesthesia for clavicle fracture and surgery. Reg Anesth Pain Med.2014;39: 256.

2. Babu Raja Shrestha, Puja Sharma. Regional Anaesthesia in Clavicle Surgery. J Nepal Med Assoc 2017;56(206):265-67.

3. Shnthanna H. Ultrasound guided selective cervical nerve root block and superficial cervical plexus block for surgeries on clavicle. Indian J Anaesth. 2014 May;58(3):327-9.

4. Franco CD VZ. Subclavian perivascular brachial plexus blocks: success with a nerve stimulator. Reg anesth Pain Med.2000;25:41-6.

5. Contractor HU, Shah VA, Gajjar VA. Ultrasound guided superficial cervical plexus and interscalene brachial plexus block for clavicular surgery. Anaesth Pain \& Intensive Care 2016;20(4):447-450

6. Kakazu C, Tokhner V Li J. In the new era of ultrasound guidance: is pneumothorax from supraclavicular block a rare complication of the past? Br J Anaesth.2014;113:190-1.

7. Taeha Ryu, Byung Tae Kil, and Jong Hae Kim, Comparison Between Ultrasound-Guided Supraclavicular and Interscalene Brachial Plexus Blocks in Patients Undergoing Arthroscopic Shoulder Surgery A Prospective, Randomized, Parallel Study.Medicine 2015 Oct; 94(40): e1726.

8. Hadzic A, Williams BA, Karaca PE, Hobeika P, Unis G, Dermksian J, et al. For outptient rotator cuff surgery, nerve block anesthesia provides superior same day recovery over general anesthesia. Anesthesiology. 2005 May;102(5):1001-1007.

9. Brown DL, Bridenbaugh LD. Cousins MJ, Bridenbaugh PO, editors. The upper extremity somatic block. Neural Blockade in Clinical Anesthesia and Pain Medicine. Philadelphia:Lippincott Williams \& Wilkins, a Wolters Kluwer business; 2009. 316-342.

10. Warren J, Thoma RB, Georgescu A. Intravenous lipid infusion in the successful resuscitation of local anesthetic-induced cardiovascular collapse after supraclavicular brachial plexus block. Anesth Analg2008; 106:1578-1580.

11. Perlas A, Lobo G, Lo N. Ultrasound-guided supraclavicular block: outcome of 510 consecutive cases. Reg Anesth Pain Med 2009; 34:171-176.

12. Bharti N, Bhardawaj N, Wig J. Comparison of ultrasound-guided supraclavicular, infraclavicular and below-C6 interscalene brachial plexus block for upper limb surgery: a randomised, observer-blinded study.Anaesth Intensive Care. 2015 Jul;43(4):468-72.

13. Royse CE, Sha S, Soeding PF. Anatomical study of the brachial plexus using surface ultrasound. Anaesth Intensive Care 2006; 34:203 -210 .

14. Cornish P. Supraclavicular block-new perspectives. Reg Anesth Pain Med 2009; 34:607-608. 
Rajbanshi et al. Comparison of Ultrasound Guided Interscalene and Supraclavicular..

15. Chun Woo Yang, Hee Uk Kwon, Choon-Kyu Cho, Sung Mee Jung, Po-Soon Kang, Eun-Su Park, Youn Moo Heo, Helen Ki Shinn. A comparison of infraclavicular and supraclavicular approaches to the brachial plexus using neurostimulation. Korean Journal of Anesthesiology 2010;58(3):260-266.

16. Susmita Bhattacharyya, KalyanBrata Mandal, Ranabir Chanda, JayantaChakrabarti, Utpal Barman and Debojyoti Das . A Comparative Study of Interscalene and Supraclavicular Approach of Brachial Plexus Block on Upper Limb Surgeries.EC Anaesthesia 2.5 (2015) : 197-204

17. Vester-Andersen T, Christiansen C, Hansen A, et al. Interscalene brachial plexus block: area of analgesia, complications and blood concentrations of local anesthetics. Acta Anaesthesiol Scand 1981; 25:81-84

18. Gonano C, Kettner SC, Ernstbrunner M, et al. Comparison of economical aspects of interscalene brachial plexus blockade and general anaesthesia for arthroscopic shoulder surgery. Br J Anaesth 2009; 103:428-433

19. Neal JM, Hebl JR, Gerancher JC, et al. Brachial plexus anesthesia: essentials of our current understanding. Reg Anesth Pain Med 2002; 27:402-428.

20. Munirama S, McLeod G. A systematic review and meta-analysis of ultrasound versus electrical stimulation for peripheral nerve location and blockade. Anaesthesia 2015;70:1084-1091.

Citation: Rajbanshi LK, Arjyal B, Khanal K, Bajracharya A. Comparison of Ultrasound Guided Interscalene and Supraclavicular Brachial Plexus Block along with Superior Cervical Plexus Block for Clavicle Fracture Surgery. JCMS Nepal. 2018;14(4):189-95. 